\title{
Application of Tools for Assessment of Risks of Economic Activity of Enterprises in the System of State Regulation of Grain Product Subcomplex in Ukraine
}

\author{
Nesterenko Svitlana \\ Department of Management \\ Dmytro Motornyi Tavria State \\ Agrotechnological University \\ Melitopol, Ukraine \\ s.nesterenko55@ukr.net
}

\author{
Martynova Liliia* \\ Department of Economic Law \\ Volodymyr Dahl East Ukrainian \\ National University \\ Severodonetsk, Ukraine \\ mar-sofi@ukr.net
}

\author{
Martynov Andrii \\ Department of Finance and Banking \\ Volodymyr Dahl East Ukrainian \\ National University \\ Severodonetsk, Ukraine \\ pubrealin@ukr.net
}

\begin{abstract}
This article explores the peculiarities of assessment of the risk of economic activity to determine the criteria of state support of enterprises of grain product subcomplex. The model of the system of formation of the general risk of economic activity of the enterprise of grainproduct subcomplex, built on the basis of the use of the provisions of game theory, is proposed. The presented model characterizes the interaction of several elements that generate risk: "nature," market, "enterprise" and elementregulator "state." The tool of complex expert assessment of the general level of risk of economic activity of the enterprise of grain-product subcomplex is proposed, which allows to implement in practice a differentiated approach when determining priorities of state regulation of grain product subcomplex in Ukraine.
\end{abstract}

Keywords - risk of economic activity, analytical tools, grain product subcomplex, state regulation

\section{INTRODUCTION}

A strategically important task of state policy and an important condition for food security of Ukraine is to ensure the sustainable development of the grain product subcomplex. Today, the grain product subcomplex is one of the most vulnerable segments of the economy in terms of resistance to risk factors caused by seasonality of grain production, natural and climatic conditions, relatively long cycle of investment capital turnover and sociodemographic factors.

In this regard, the relevant direction of the study is the development and scientific justification of a set of measures to ensure state support for the development of grain product subcomplex within the framework of the common state system of regulatory and legal regulation of the economy.

The key issue of building an effective system of state support for the development of the grain product subcomplex is the definition of criteria for the identification of objects requiring state support. In our opinion, an important tool for determining the expediency of state assistance for enterprises of grain product subcomplex is the assessment of the level of risk of economic activity. This makes it necessary to study the tools for assessing the risks of economic activity at grain product subcomplex enterprises in order to form an effective mechanism for determining the expediency and size of state support for the functioning and development of grain product subcomplex enterprises in Ukraine.

The problems of development of grain product subcomplex in the context of anti-risk management have been investigated in the works of such researchers as: Kovaleva A.M. [1], Kozak A.A. [53], Bondar A.V. [3], Kirilenko I.G. [4], Zavita A.P. [5], Dankevich E. M. [6]. Fundamental works of such scientists as F. Knight [7], J. Neiman, A. Morgenstern [8], T. Bedford [9], M. Crouch [10], M. Gregory [11], P. Hopkin [12] are devoted to the study of issues of identification and assessment of risks of business activity. Despite extensive research on risk management of enterprises in modern economic science, the problem of formation of effective analytical tools for risk management of enterprises of grain product subcomplex is not finally solved today. Special attention is paid in the framework of the presented study to the issues of using the tools of assessment of risks of economic activity in enterprises for determining the criteria of expediency and the level of necessary state support of enterprises of grain product subcomplex.

This can become the basis for using a differentiated approach within the framework of a centralized system of measures of normative and legal nature aimed at state support of subjects of grain product subcomplex in Ukraine.

\section{MODEL}

\section{A. Theil Index}

On the basis of the synthesis of the results of the risk factors study using expert estimates, the main groups of risk factors of the economic activity of the grain-product subcomplex enterprises have been identified:

- "Nature," which characterizes the factors caused by unpredictable change of natural and climatic 
conditions and, accordingly, fluctuations in the yield of cereals

- "Market," which summarizes market risk factors that cause favorable or unfavorable external conditions for the economic activity of the grainproducing enterprise

- "Enterprise" comprising internal risk factors arising from the nature of the enterprise itself.

\section{B. Model}

The construction of a holistic model of risk formation needs to be supplemented by certain groups of risk factors, an additional element-regulator in the name of the state, together provides the formation of a generalizing vector of risk of the enterprise and is the basis for the construction of a model of formation of aggregate risk of economic activity of the enterprise of grain product subcomplex (Figure 1).

The practical implementation of the model is provided by the developed mathematical tools and procedures of comprehensive expert assessment of the general level of risk of economic activity of grain producing enterprises, including determination of the structure of risk factors and their expert assessment (Table I).

At the same time the indicator $r_{n m}$ represents the expert assessment of the level of $m$-th risk by the $n$-th expert, and indicator $Y\left(r_{n m}\right)$ defines the specific weight of $m$-th risk in the general risk assessment determined by the $n$ - $t$ th expert, $d_{n}$ describes the degree of confidence in the estimates of individual experts, which is expressed by setting the specific weight of their assessment in the general assessment of risk factors.

Area of formation of general risk vector of business activity of the enterprise

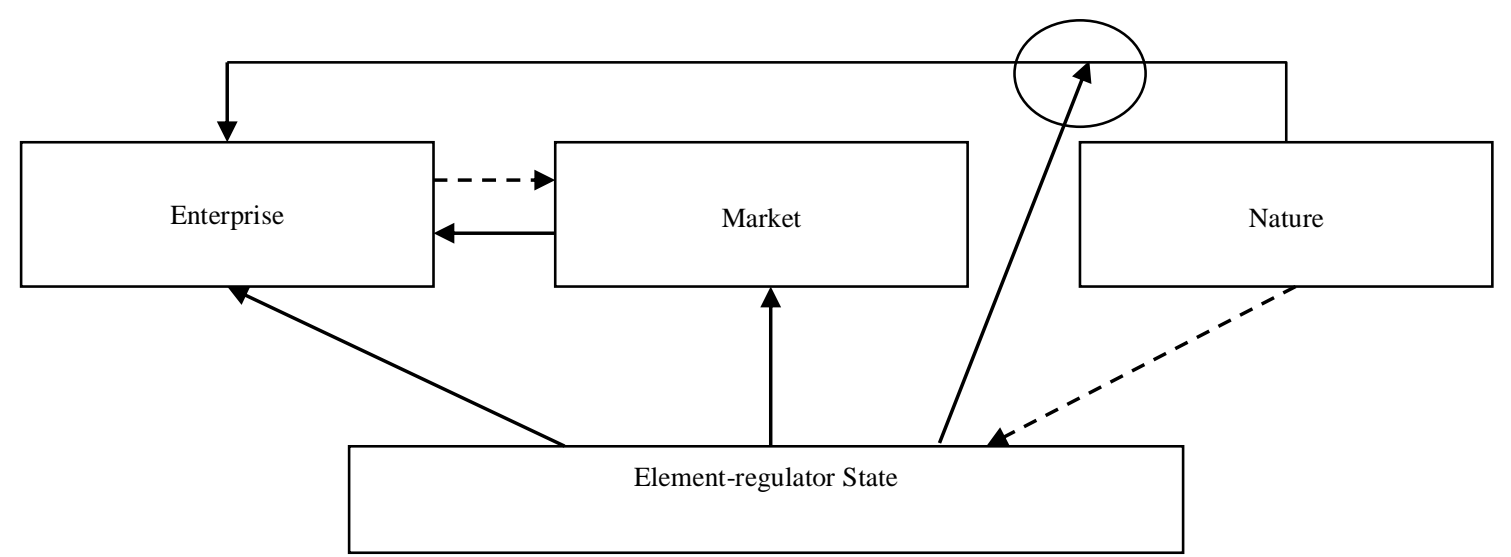

Fig. 1. Model of the system for the formation of the general risk of economic activity of the enterprise of grain product subcomplex

TABLE I. SCHEME OF COMPLEX EXPERT ASSESSMENT OF THE GENERAL LEVEL OF RISK OF ECONOMIC ACTIVITY OF THE GRAIN PRODUCT SUBCOMPLEX ENTERPRICE

\begin{tabular}{|c|c|c|c|c|c|}
\hline $\begin{array}{l}\text { Risk } \\
\text { factor }\end{array}$ & Expert 1 & Expert 2 & Expert 3 & ... & Expert n \\
\hline $\begin{array}{c}\text { Share of the expert's } \\
\text { assessment in the overall } \\
\text { assessment }\end{array}$ & $\mathrm{d}_{1}$ & $\mathrm{~d}_{2}$ & $d_{3}$ & $\cdots$ & $\mathrm{d}_{\mathrm{n}}$ \\
\hline \multirow{2}{*}{ Risk factor 1} & $\mathrm{r}_{11}$ & $r_{21}$ & $r_{31}$ & $\ldots$ & $\mathrm{r}_{\mathrm{n} 1}$ \\
\hline & $\mathrm{Y}\left(\mathrm{r}_{11}\right)$ & $\mathrm{Y}\left(\mathrm{r}_{21}\right)$ & $\mathrm{Y}\left(\mathrm{r}_{31}\right)$ & $\ldots$ & $\mathrm{Y}\left(\mathrm{r}_{\mathrm{n} 1}\right)$ \\
\hline \multirow{2}{*}{ Risk factor 2} & $\mathrm{R}_{12}$ & $r_{22}$ & $r_{32}$ & $\ldots$ & $r_{n 2}$ \\
\hline & $\mathrm{Y}\left(\mathrm{r}_{12}\right)$ & $\mathrm{Y}\left(\mathrm{r}_{22}\right)$ & $\mathrm{Y}\left(\mathrm{r}_{32}\right)$ & $\ldots$ & $\mathrm{Y}\left(\mathrm{r}_{\mathrm{n} 2}\right)$ \\
\hline \multirow{2}{*}{ Risk factor 3} & $\mathrm{R}_{13}$ & $r_{23}$ & $r_{33}$ & $\ldots$ & $r_{n 3}$ \\
\hline & $\mathrm{Y}\left(\mathrm{r}_{13}\right)$ & $\mathrm{Y}\left(\mathrm{r}_{23}\right)$ & $\mathrm{Y}\left(\mathrm{r}_{33}\right)$ & $\ldots$ & $\mathrm{Y}\left(\mathrm{r}_{\mathrm{n} 3}\right)$ \\
\hline \multirow{2}{*}{$\cdots$} & $\ldots$ & $\ldots$ & $\ldots$ & $\ldots$ & $\ldots$ \\
\hline & $\ldots$ & $\ldots$ & $\ldots$ & $\ldots$ & $\ldots$ \\
\hline \multirow{2}{*}{ Risk factor $\mathrm{m}$} & $\mathrm{R}_{1 \mathrm{~m}}$ & $\mathrm{r}_{2 \mathrm{~m}}$ & $r_{3 \mathrm{~m}}$ & $\ldots$ & $r_{n m}$ \\
\hline & $\mathrm{Y}\left(\mathrm{r}_{1 \mathrm{~m}}\right)$ & $\mathrm{Y}\left(\mathrm{r}_{2 \mathrm{~m}}\right)$ & $\mathrm{Y}\left(\mathrm{r}_{3 \mathrm{~m}}\right)$ & $\ldots$ & $\mathrm{Y}\left(\mathrm{r}_{\mathrm{nm}}\right)$ \\
\hline
\end{tabular}

Synthesis of the obtained expert assessments, taking into account a zone risk factor, provides a model of complex expert assessment of the general level of risk of the economic activity of the grain product subcomplex enterprise

$$
\mathrm{R}_{\mathrm{t}}=k_{a} \times \sum_{k=1}^{k=m}\left(r_{w k} \times Y_{w k}\right)
$$

where $R_{t}$ is the total risk level, $k_{a}$ is the zone risk factor, $r_{w k}$ is the weighted average assessment of the $k$ risk factor, $Y_{w k}$ is the weighted average specific weight of the $k$ risk factor in the overall assessment of the risk of the economic activity of the grain product enterprise, the index value $k=1,2,3, \ldots \mathrm{m}$. Here, $m$ is the total number of risk factors selected for evaluation. 
$R_{\text {irk }}$ calculation is carried out for each individual risk factor according to this formula

$$
\mathrm{R}_{\mathrm{irk}}=\sum_{b=1}^{b=n}\left(r_{k b} \times d_{k b}\right)
$$

where $r_{k b}$ - assessments of risk factors made by experts, $d_{k b}$ weighting factors that characterize the degree of confidence of individual experts assessments (weight of the expert's assessment in the general risk assessment)

The calculation $Y_{i r k}$ is carried out for each individual risk factor according to the following formula

$$
Y_{i r k}=\sum_{b=1}^{b=n}\left(Y_{k b} \times d_{k b}\right)
$$

where $Y_{k b}$ assessments of the specific weight of risk factors in the general risk assessment of the business activity of the grain product enterprise, carried out by experts.

\section{DATA}

On the basis of the proposed tools of comprehensive assessment of risks of economic activity of grain product enterprises using specially developed questionnaires for the survey of experts and specialists, an expert assessment of risks of economic activity of grain product enterprises of the Lugansk region has been carried out on the example: JSC "Agroton," LLC "Starobelsky Elevator" and LLC "Aydarsky Pekar". Expert assessment of risks of economic activity of grain product enterprises has been carried out in two stages. In the first stage, the main risk factors are identified and structured into risk factor groups, and in the second stage, the degree of influence of risk factor groups on the general level of risk of economic activity of grain product enterprises has been directly assessed, and expert assessment of risk levels generated by certain groups of risk factors of economic activity of grain product enterprises was carried out.

The main groups of risk factors of economic activity of grain processing enterprises, according to Fig. 1, include the following main elements: A) "Nature" (symbol $N)$; B) "Market" (symbol $M$ ); C) "Enterprise" (symbol $E$ )

The regulator element represented by the state is not included in the risk factors due to its alleged rational behavior, as well as the special role of the state aimed at carrying out measures of an anti-risk nature.

As experts, leading specialists of grain product complex enterprises of Lugansk region of JSC "Agroton," LLC "Starobelsky Elevator" and LLC "Aidarsky Pekar" have been involved. Each of the experts is assigned the same degrees of trust, which expresses the indicator of the specific weight of the expert's assessment in the general assessment of groups of risk factors of economic activity of grain-producing enterprises.

At the same time, the assessment of risk factor groups $N$ "Nature" and $M$ "Market" is common for all enterprises, and the assessment of risk factor group $E$ "Enterprise" varies according to the peculiarities of the enterprise.

Qualitative assessments used to assess the level of risks generated by certain groups of risk factors of the economic activity of grain product enterprises. At the same time, the scale of qualitative assessment of risk level includes the following values: "very low", "low", "medium", "high" and "very high". In addition to qualitative assessment, the expert is given an assessment of the specific weight of risk factor groups in the formation of the total level of risk of economic activity in percent. At the same time, the total amount of assessments of the specific weight of groups of risk factors of economic activity of enterprises, determined by the expert, should be $100 \%$.

In order to conditionally formalize the assessment of risk levels for certain groups of risk factors ( $N$ - "Nature", $M$ - "Market" and $E$ - "Enterprise"), we propose to apply the following scale of ranking of qualitative assessments of risk level of economic activity of grain product enterprises (Table II).

TABLE II. RATING SCALE OF QUALITATIVE ASSESSMENTS OF THE LEVEL OF RISK OF ECONOMIC ACTIVITY AND PRIORITIES OF STATE SUPPORT OF ENTERPRISES OF GRAIN PRODUCT SUBCOMPLEX

\begin{tabular}{|l|c|c|}
\hline $\begin{array}{c}\text { Qualitative assessment } \\
\text { of risk level }\end{array}$ & $\begin{array}{c}\text { Rank } \\
\text { value }\end{array}$ & $\begin{array}{c}\text { Priority level of state } \\
\text { support }\end{array}$ \\
\hline Very low & $0-1$ & $\begin{array}{c}5 \text { priority (lowest priority } \\
\text { of state support) }\end{array}$ \\
\hline Low & $1-2$ & $\begin{array}{c}4 \text { priority (low priority of } \\
\text { state support) }\end{array}$ \\
\hline Medium & $2-3$ & $\begin{array}{c}3 \text { priority (medium } \\
\text { priority of state support) }\end{array}$ \\
\hline High & $3-4$ & $\begin{array}{c}2 \text { priority (high priority of } \\
\text { state support) }\end{array}$ \\
\hline Very high & $4-5$ & $\begin{array}{c}\text { 1 priority (highest priority } \\
\text { of state support) }\end{array}$ \\
\hline
\end{tabular}

\section{EMPIRICAL RESULT}

The results of expert assessment of risks of economic activity of enterprises of grain product subcomplex of Lugansk region on the example: JSC "Agroton," LLC "Starobelsky Elevator" and LLC "Aidarsky Pekar" are given in Table 3.

According to the data of Table 3, the following weighted average assessments of the specific weight of risk factor groups in the formation of the general level of risk of economic activity for grain producing enterprises were obtained: $N$ - "Nature" 17.5\%; $M$ - "Market" 44\%; $E$ - "Enterprise" 38.5\%.

On the basis of the expert assessment, the weighted average assessemnt of risk levels generated by groups of risks of economic activity of grain product enterprises are also reflected in the form of rank values: $N$ - "Nature" 2.7; $M$ - "Market" 3.9; E - "Enterprise": JSC "Agroton" 2.5; LLC "Starobelsky Elevator" 3.2; LLC "Aidarsky Pekar" 4.4.

According to the obtained expert assessments of risk levels generated by certain groups of risk factors of economic activity of grain product enterprises, it was determined that the relatively high level of risk is inherent in the group of risk factors $M$ "Market," the average level of risk is generated by the group of factors $N$ "Nature," and in the group of factors $E$ "Enterprise" assessments vary according to the peculiarities of economic activity of economic entities. 
TABLE III. RESULTS OF EXPERT ASSESSMENT OF RISKS OF ECONOMIC ACTIVITY OF GRAIN PRODUCT COMPLEX ENTERPRISES OF LUGANSK REGION: JSC “AGROTON”, LLC “STAROBELSKY ELEVATOR” AND LLC “AIDARSKY PEKAR”

\begin{tabular}{|c|c|c|c|c|c|c|c|c|c|}
\hline \multirow{4}{*}{ Expert } & \multirow{4}{*}{$\begin{array}{l}\text { Share of } \\
\text { the } \\
\text { expert's } \\
\text { assessment } \\
\text { in the } \\
\text { general } \\
\text { assessment }\end{array}$} & \multicolumn{8}{|c|}{ Assessment of groups of risk factors } \\
\hline & & \multicolumn{2}{|c|}{$N-\ll$ Nature» } & \multicolumn{2}{|c|}{$M-\ll$ Market» } & \multicolumn{4}{|c|}{$E-\ll$ Enterprise» } \\
\hline & & \multirow{2}{*}{$\begin{array}{l}\text { assessment } \\
\text { of specific } \\
\text { weight, \% }\end{array}$} & \multirow{2}{*}{$\begin{array}{c}\text { risk level } \\
\text { assessment }\end{array}$} & \multirow{2}{*}{$\begin{array}{l}\text { assessment } \\
\text { of specific } \\
\text { weight, \% }\end{array}$} & \multirow{2}{*}{$\begin{array}{c}\text { risk level } \\
\text { assessment }\end{array}$} & \multirow{2}{*}{$\begin{array}{l}\text { assessment } \\
\text { of specific } \\
\text { weight, \% }\end{array}$} & \multicolumn{3}{|c|}{ risk level assessment } \\
\hline & & & & & & & $\begin{array}{c}\text { JSC } \\
\text { "Agroton" }\end{array}$ & $\begin{array}{c}\text { LLC } \\
\text { "Starobelsky } \\
\text { Elevator" }\end{array}$ & $\begin{array}{c}\text { LLC } \\
\text { "Aidarsky } \\
\text { Pekar" }\end{array}$ \\
\hline 1 & 2 & 3 & 4 & 5 & 6 & 7 & 8 & 9 & 10 \\
\hline 1 & 0,1 & $5 \%$ & 4 & $70 \%$ & 5 & $25 \%$ & 3 & 4 & 5 \\
\hline 2 & 0,1 & $10 \%$ & 3 & $10 \%$ & 5 & $80 \%$ & 2 & 3 & 4 \\
\hline 3 & 0,1 & $10 \%$ & 3 & $40 \%$ & 3 & $50 \%$ & 1 & 2 & 3 \\
\hline 4 & 0,1 & $10 \%$ & 2 & $45 \%$ & 4 & $45 \%$ & 3 & 4 & 4 \\
\hline 5 & 0,1 & $15 \%$ & 3 & $45 \%$ & 4 & $40 \%$ & 3 & 3 & 5 \\
\hline 6 & 0,1 & $30 \%$ & 2 & $35 \%$ & 2 & $35 \%$ & 4 & 4 & 5 \\
\hline 7 & 0,1 & $25 \%$ & 4 & $25 \%$ & 5 & $50 \%$ & 2 & 3 & 5 \\
\hline 8 & 0,1 & $30 \%$ & 1 & $50 \%$ & 3 & $20 \%$ & 4 & 4 & 5 \\
\hline 9 & 0,1 & $15 \%$ & 2 & $70 \%$ & 5 & $15 \%$ & 1 & 2 & 4 \\
\hline 10 & 0,1 & $25 \%$ & 3 & $50 \%$ & 3 & $25 \%$ & 2 & 3 & 4 \\
\hline $\begin{array}{c}\text { Average } \\
\text { value }\end{array}$ & 0,1 & $17,5 \%$ & 2,7 & $44,0 \%$ & 3,9 & $38,5 \%$ & 2,5 & 3,2 & 4,4 \\
\hline
\end{tabular}

The total weighted average risk assessment of the economic activity of grain product enterprises, calculated on the example of JSC "Agroton," LLC "Starobelsky Elevator" and LLC "Aidarsky Pekar" according to formula 1, is:

1) For JSC "Agroton" $R_{t}=2,71$. According to the rating scale of qualitative assessments of the level of risk of economic activity of enterprises of grain-product subcomplex, given in Table 2, the obtained value $R_{t}=2.71$ corresponds to the average level of risk and the third level of priority of state support.

2) For LLC "Starobelsky Elevator" $R_{t}=2.94$. the obtained value of the qualitative assessment of the risk level $\mathrm{R}_{\mathrm{t}}=2.94$ also characterizes the average risk level and corresponds to the third level of priority of state support.

3) For LLC "Aidarsky Pekar" $\mathrm{R}_{\mathrm{t}}=3.34$. The obtained calculated value of the indicator of the level of risk of economic activity at the enterprise $R_{t}=3.34$ is interpreted as an indicator of the high level of risk and corresponds to the second (high) priority of state support.

The received total weighted average assessment of the risk of economic activity for enterprises of grain product subcomplex of Lugansk region, expressed in rank form. In accordance with the ranking scale of qualitative assessments of the level of risk of economic activity of grain product enterprises, a qualitative characteristic of the obtained numerical values of the level of risk is presented.

A set of state regulatory measures is implemented on the basis of state support programs for the grain product complex, which provide for compensation and grant reimbursement, lending, as well as full financing.

Importance is attached to the mechanism of price regulation for grain and its processed products in order to ensure the process of further expanded reproduction of their production. At the same time, the key role is to eliminate or minimize the difference in prices for agricultural and industrial products, which should be ensured primarily by the use of guaranteed prices for agricultural products and state compensation to the producer of the difference between market and state prices.
One of the main and effective methods of risk management in the enterprises of grain product subcomplex is the system of agrarian insurance with the support of the state, which allows the manufacturer to compensate for the losses incurred by it as a result of unpredictable risk factors.

The obtained empirical data are the basis for determining the priority of state support for specific enterprises on the basis of an assessment of the general level of risk of economic activity, which ensures the use of a differentiated approach in the system of state stimulation of the development of grain product subcomplex.

\section{CONCLUSION}

Thus, according to the results of the conducted study, mathematical tools and procedures of complex expert assessment of the risk of economic activity for enterprises of grain product subcomplex, which were tested on the example of enterprises of grain product subcomplex of Lugansk region: JSC "Agroton," LLC "Starobelsky Elevator" and LLC "Aidarsky Pekar". The developed proposals provide prerequisites for increasing the level of validity of management decisions in the field of management of risks of economic activity of grain product enterprises. The proposed analytical tools can be used for formation of priorities of state regulation of grain-product subcomplex development in Ukraine.

\section{REFERENCES}

[1] O.M. Kovaleva, "Assessment of the development potential of the grain sub-complex of the economy of Ukraine," Global and national economic challenges, vol. 7, pp. 155-159, 2015. (in Ukrainian)

[2] O.A. Kozak, O.Y. Grishchenko, "Development of grain industry of Ukraine at the present stage," Economy of agro-industrial complex, vol. 1, pp. 38-47, 2016. (in Ukrainian)

[3] A.V. Bondar, "Peculiarities of pricing in grain products of the subcomplex of Ukraine," Economics of market relations, vol. 11, pp. 127-133, 2013. (in Ukrainian)

[4] I.G. Kirilenko, "Formation of grain market of Ukraine: development strategy," Economy of agro-industrial complex, vol. 9, pp. 79-84, 2009. (in Ukrainian)

[5] A.P. Zavita, T.V Didoenko, "Ukrainian market of cereals and technical crops in the context of development prospects of the agricultural sector of the economy," Collection of scientific works of Podol State Agricultural and Technical University. Ser. economic sciences, vol. 24, part 3, pp. 58-67, 2016. (in Ukrainian) 
[6] E.M. Dankevich, "Integration processes on the grain market," Bulletin of Sumy National Agrarian University, Series. Economics and Management, vol. 5(56), pp. 58-62, 2013. (in Ukrainian)

[7] F.H. Knight, "Risk, Uncertainty and Profit", english translation, 360 p, 2003. (in Russian)

[8] J. Neiman, O. Morgenstern, "Game theory and economic behavior", translation from English edited by T.T. Vorobyeva, 708 p, 1970. (in Russian)

[9] T. Bedford, R. Cooke, "Probabilistic Risk Analysis: Foundations and Methods", Cambridge: Cambridge University Press, 2001.
[10] M. Crouhy, D. Galai, R. Mark, "Risk Management," 2nd ed. New York: McGraw-Hill, 2012.

[11] M. Gregory, "Enterprise Risk Management: A Methodology for Achieving Strategic Objectives," Wiley and SAS Business Series, Wiley, 2008.

[12] P. Hopkin, "Fundamentals of Risk Management: Understanding, Evaluating and Implementing Effective Risk Management", Kogan Page, 2010. 